\title{
Internationalisation and Placement Activity in the UK National Health Service
}

\begin{abstract}
This chapter presents and discusses the findings from a survey conducted in the North West of England designed to gauge overall patterns of international exposure amongst all cadres of staff in the UK's National Health Service.
\end{abstract}

Keywords Internationalisation - Overseas placements - Current usage levels (in NHS)

\section{INTRODUCTION}

Very little is known about the prevalence of international exposure across the NHS. In contrast to the highly accurate and detailed NHS workforce summaries which are available from central government sources, information specifically concerned with professional volunteering placements is often piecemeal and deals only with discrete settings or departments. Organisations responsible for volunteer deployments, such as Voluntary Service Overseas or the Tropical Health and Education Trust, have conducted some small-scale surveys of their own volunteers, but this gives little impression of the overall propensity to engage in international placements and may give the impression that the phenomenon is far more common than it really is.

We thought it would be useful to contextualise the findings on learning outcomes derived from the qualitative interviews with professional 
volunteers within an overall understanding of prevalence and patterns of this form of mobility. Chapter 1 raised concerns about the growing expectation of mobility in healthcare professions. It also positioned the study in the context of the evolving skills agenda in the NHS and the emphasis on soft skills and multidisciplinary team working. Both of these issues raise the issue of inclusivity and the importance of opening up opportunities for all staff across cadres and over the life course. Chapter 1 also raised concerns about the financial implications that these forms of mobility generate in terms of providing staff cover. The survey findings provide an important context for these discussions.

\section{The NHS STAFF SURVEY}

Survey research is often hampered by non-response skewing findings. (See, for example, Bhatta 2009; Baruch Y and Holtom 2008; Evans and Mathur 2005; Barclay et al. 2002.) We anticipated a greater response rate to an online survey from those staff who had experienced international placements than those who had not. Pilot work supported this assertion as staff in technical areas or laboratory work who had not experienced international mobility immediately interpreted the survey, despite assurances, as implying that they were not eligible to respond. We were particularly keen to sample a wide range of staff, including those whom we may expect to have had less opportunity to engage in international placements. With this objective in mind we decided not to opt for a blanket email/online survey but rather to attempt to gather results on a face-to-face basis to optimise completion rates.

Attempting to sample the whole population of ( 1.3 million) NHS employees could only have been achieved with great difficulty and probably only through an online survey tool administrated via Trusts. Our relationships with institutions in the North West enabled us to target a subpopulation that we consider to be broadly representative of the wider NHS. We therefore decided to focus our recruitment on a small number of hospitals and community medical centres within a single NHS region in the North West of England. These included two large regional teaching hospitals: Salford Royal Infirmary, Salford, and Wythenshawe Hospital (the University Hospital of South Manchester NHS Foundation Trust). We also undertook recruitment at Liverpool Women's Hospital, which is a major obstetrics, gynaecology and neonatology research hospital; and Liverpool Community Health Trust, which is a large regional hub for the administration of over 3000 NHS staff in the North West. Data from these institutions were supplemented with findings gathered from the 
2015 Royal College of Nursing Research Conference, and a large Community-Based Medical Education training event held in April 2015.

Following a successful pilot survey conducted at Liverpool Women's Hospital, we decided it would be most effective to target our activity on busy public areas within each site, such as main entrances, cafeterias and arterial thoroughfares. We reasoned that such areas would be used by the whole range of hospital employees, and there would be the best chance of accessing a broad sample. The research team worked in groups of three or four, identifying potential respondents as those with NHS identification badges. At the Wythenshawe site, we were also able to attend three large staff orientation events organised by the hospital's HR department. These events, which were essentially held to welcome new starters at the hospital, attracted a wide range of people from different staff groups.

The survey was designed to be conducted on a one-to-one basis by researchers using an iPad running eForms software (University of Manchester 2015). It was deliberately framed to be very quick to complete - around two minutes - and was anonymous. Using eForms streamlined the process of participant engagement and meant that the survey could be conducted wholly electronically. Once a member of staff had been approached and agreed to take part, they were given the iPad and worked through the various simple sections of the survey (see below). Respondents were automatically assigned a code number by the eForms system, and their anonymous responses were stored offline on the iPad. Data were downloaded to a central online database at the end of each fieldwork session. Field work was conducted in the various settings between January and August 2015. The survey consisted of seven sections.

\section{CADRE}

The categorisations we listed were derived from eight standard employment cadres currently utilised by human resource departments across the NHS:

1. Allied health professionals

2. Healthcare scientists

3. Medical and dental

4. NHS infrastructure

5. Scientific and technical

6. Ambulance staff

7. Nursing midwifery and health visitors

8. Clinical support staff 


\section{Career Stage}

1. Pre-university

2. Student

3. Early-career

4. Mid-career

5. Experienced/senior

6. Post retirement

Subsequent sections were related to age, gender and nationality. Those who indicated that they had spent time in another country, either as an employee or volunteer, proceeded to a final section (6), which focused on specific details for each time of stay abroad. This section included questions on the economic status of the country (high, middle or low income), and the career stage they were at when abroad: pre-university; student; early-career; mid-career; experienced /senior; post retirement. We also collected basic qualitative information at this point relating to length of stay and the type of placement if this was relevant. At the conclusion of the survey respondents who indicated that they would like to be sent information on the outcome of the study were asked to share an email address or phone number. A copy of the survey is given in Appendix 2.

\section{RESULTS}

SPSS software was used to provide basic descriptive statistics and isolate the key features of the data. Overall, a total of 911 NHS employees completed the survey.

\section{Sample Characteristics}

Table 2.1 shows the relative proportions of different staff cadres currently employed in the NHS as a whole (column A), along with the relative percentages of staff specifically employed in the North-West region where the staff survey was conducted (NHS-ESR 2013) (column B). Column C shows the proportion of respondents from different staff groups who actually took part in the survey. Column $\mathbf{D}$ gives the proportion of staff by cadre who were interviewed for the qualitative arm of the MOVE study.

It can be seen that in line with our broad hypothesis, the relative proportion of staff that go to make up the NHS workforce nationally 
Table 2.1 The survey population compared to the NHS workforce and interview sample

\begin{tabular}{lcccc}
\hline Staffgroup & $\begin{array}{l}\text { (A) Relative } \\
\text { percentages of } \\
\text { staff in the total } \\
\text { NHS workforce } \\
\text { (\%) }\end{array}$ & $\begin{array}{l}\text { (B) Relative } \\
\text { percentages of staff in } \\
\text { the North West } \\
\text { region. (NHS-ESR } \\
\text { 2013) }(\%)\end{array}$ & $\begin{array}{l}\text { (C) Survey } \\
\text { respondents } \\
\text { (\%) }\end{array}$ & $\begin{array}{l}\text { (D) } \\
\text { Interviewees } \\
\text { (\%) }\end{array}$ \\
\hline $\begin{array}{l}\text { Nurse/ } \\
\text { midwife/ } \\
\text { health visitor }\end{array}$ & 30 & 31 & 31 & 32 \\
$\begin{array}{l}\text { Allied health } \\
\text { professionals } \\
\begin{array}{l}\text { Medical and } \\
\text { dental }\end{array}\end{array}$ & 8 & 6 & 14 & 13 \\
$\begin{array}{l}\text { Clinical } \\
\text { support staff }\end{array}$ & 10 & 10 & 32 & 35 \\
$\begin{array}{l}\text { NHS } \\
\text { infrastructure } \\
\text { Ambulance } \\
\text { staff }\end{array}$ & 16 & 27 & 10 & 4 \\
$\begin{array}{l}\text { Health } \\
\text { scientist }\end{array}$ & 29 & 20 & 7 & 14 \\
\hline
\end{tabular}

Source: Created by the authors.

(column A) is very closely matched to the proportion of staff employed in the North-West Region (column B). This supports our contention that the survey data obtained in the context of a single region could be reasonably expected to reflect the situation across the entire organisation - at least in relation to the kind of non-regionally specific issues we are concerned with. The only staff cadre with any significant variation between regional and national levels is infrastructure, and even with this group, there is only a $4 \%$ difference. The slightly higher proportion of infrastructure staff relative to the national figure may be due to a variety of factors but is likely to reflect the particular organisation and management idiosyncrasies which have evolved in the North West. In the context of this survey (and indeed the wider MOVE project), these kinds of variation are unlikely to have a significant impact. Although our sampling process was largely opportunistic (see above), the sampling process achieved the level of diversity that we had planned for (column C). Significantly, the percentage of nurse/midwife/health visitor staff we engaged with accurately 
reflects both the national and regional figures. However, medical and dental were over-represented and clinical support staff and infrastructure staff were underrepresented.

\section{International Placements}

Table 2.2 provides the relative percentages of staff from the various cadres who had engaged in overseas activity at some stage in their educational career. It can be seen that overall, $42 \%$ of those in our survey (389) reported at least one overseas placement experience.

The three highest responding groups were medical and dental with 140 respondents (36\%); nursing/midwifery and health visitor $(21 \%)$; and allied health professionals $(18 \%)$. The remaining groups were composed of clinical support staff (15\%); NHS infrastructure (4\%); health scientists $(4 \%)$; and ambulance staff $(2 \%)$

It is no great surprise that in line with the focus of much of the literature on volunteering and placements within health and medical contexts the highest proportion of staff with overseas experience were medical and dental (see, for example, BMA 2009; RCN 2010). This is likely to be a reflection of the way in which medical training in the UK has traditionally valued the experience that students gain from time abroad. The option is to participate in an overseas placement often being built into, or at least available through UK-based clinical training programmes (Gedde et al. 2011; Tooke 2009).

It is significant in the context of current policy initiatives that, although the next most populous group in terms of placement activity were nurses, midwives and health visitors (21.1\% of volunteers), the

Table 2.2 Volunteering experiences by cadre

\begin{tabular}{lc}
\hline Professional group & Proportion of sample \\
\hline Nurse/midwife/health visitor & $(21 \%) 82$ \\
Allied healthcare professionals & $(18 \%) 71$ \\
Medical and dental & $(36 \%) 140$ \\
Support to clinical staff & $(15 \%) 58$ \\
NHS infrastructure & $(4 \%) 15$ \\
Ambulance staff & $(2 \%) 8$ \\
Health scientist & $(4 \%) 5$ \\
Total & 389 \\
\hline
\end{tabular}

Source: Created by the authors. 
third group, allied health professionals, was of a similar size (18.3\%). This group as a whole has not traditionally engaged in overseas activity as part of NHS-based training, although particular sub-groups including physiotherapists and speech and language therapists do have a more active tradition of incorporating international placements and training (Rodger et al. 2008). The relatively high percentage of staff in this group as a whole may indicate that there are a large number of individuals who have managed to navigate their way through the process of organising and undertaking an overseas outing within the demands of their everyday roles, and not necessarily with the structural support enjoyed by some of their colleagues. The detailed makeup of such a group would be usefully analysed in further work, as they will have a first-hand experience of just where systemic and organisational barriers can develop.

It is interesting to reflect on the perceptions of one survey respondent (a theatre technician) who had not experienced an international placement himself but had views about their relative contribution to learning:

It doesn't seem to be offered to people [theatre assistants] in the operating theatres cos we're on the coal face doing the important work [laughs]... Value? Possibly, possibly not. I'd love to go abroad and see how other people work but value - possibly not. I've spoken to people who've gone abroad and they've come back and they don't seem to bring very much back with them to be quite honest. They tell you how - people who have been to Africa, for example, or India - they come back and they say it's been great for them to help, to see how other people work. But the only thing they seem to bring back is that they're really happy to be back and they're not working in those conditions anymore. You know, the NHS, seems to be a good place to work really and they realise that when they come back and they see how the rest of the world works.

\section{Placement Location}

Table 2.3 shows the broad socio-economic status of the countries where staff reported having gained overseas experience. $20 \%$ (77) had worked in a high-income location; $22 \%(86)$ in a middle-income location; and $58 \%$ (226) in a low-income location.

Over half of the respondents reported an experience in a low-resource setting. The clear tendency for professional volunteering to be focused on low-income locations such as sub-Saharan Africa and India is borne out in 
Table 2.3 Economic status of locations where staff reported overseas experience

\begin{tabular}{lc}
\hline Location & \% of staff \\
\hline High-income & 20 \\
Middle-income & 22 \\
Low-income & 58 \\
\hline
\end{tabular}

Source: Created by the authors.

the literature. As early as the late 1980s Graitcer et al. (1989) were suggesting that 100,000 non-governmental sponsored volunteers worked in developing countries, with much smaller numbers choosing to go to more wealthy locations. More recent estimates by the Department of Health have supported this (Department of Health 2010a), and at a broader corporate level, a recent survey by internet placement brokers Go Overseas noted that the top five most searched-for locations for voluntary work and placement opportunities in 2014 were the Philippines, Thailand, India, Nepal and Cambodia (Go Overseas 2014). Interestingly, the Philippines headed the list at the time of their survey due to people specifically wishing to help with the response to typhoon Haiyan, which struck the area in late 2013. From a more functional perspective Bhatta et al. (2009) have outlined how the tendency for lowincome locations to be favoured over high-income ones can also be influenced by placement providers. Well-established organisations such as VSO concentrate their efforts exclusively on low-income areas, and contextually too, the idea of 'overseas volunteering' is rarely associated with locations such as America or Western Europe unless the activities undertaken are concerned with low-income or deprived sectors. Volunteering in highincome settings can evoke a slightly different kind of motivations, and there can be a shift from the purely altruistic to something with a more personal focus; activities, while still essentially 'voluntary', can become labelled more as internships, with a more overt focus on work experience and career development.

\section{Gender}

The overall sample included more females than males (519 females compared to 392 males). This echoes the gender balance in the NHS. A recent report by the National Health Service Employers (NHSE 2016) indicates 
that around 77\% NHS employees are female. Figures from NHS Digital (NHSD 2016) note that it is only in the cadre represented by ambulance staff that male employees predominate ( $62 \%$ are male).

Our sample indicated that 217 females and 172 males had voluntary or overseas experience. Table 2.4 shows the overall gender balance among volunteers across the different staff grades.

In terms of females, nurses, midwives and health visitors reported the most experience of international placements (34\%), followed by medical/ dental (27\%). Amongst males, medical/dental cadres represented the largest group; (48\%), followed by Allied Health Professionals (25\%) (Table 2.5).

Within the individual staff group, it can be seen that the balance between male and female volunteers broadly reflects the gender balance

Table 2.4 Overall proportion of staff by gender volunteering in another country

\begin{tabular}{lllc}
\hline Professional group & Female & Male & Totals $(M$ \& FM) \\
\hline Nurse/midwife/health visitor & $34 \%(74)$ & $5 \%(8)$ & 82 \\
Medical and dental & $27 \%(58)$ & $48 \%(82)$ & 140 \\
Support to clinical staff & $17 \%(38)$ & $11 \%(20)$ & 58 \\
NHS infrastructure & $6 \%(13)$ & $1 \%(2)$ & 15 \\
Health scientist & $2 \%(5)$ & $6 \%(10)$ & 15 \\
Allied healthcare professionals & $1 \%(28)$ & $25 \%(43)$ & 71 \\
Ambulance staff & $1 \%(1)$ & $4 \%(7)$ & 8 \\
Totals & $100 \% / 217$ & $100 \% / 172$ & 389 \\
\hline
\end{tabular}

Source: Created by the authors.

Table 2.5 Gender breakdown by cadre (international volunteering)

\begin{tabular}{lllc}
\hline Professional group & Female & Male & Total (M er FM) \\
\hline Nurse/midwife/health visitor & $90 \%(74)$ & $10 \%(8)$ & 82 \\
NHS infrastructure & $87 \%(13)$ & $13 \%(2)$ & 15 \\
Support to clinical staff & $66 \%(38)$ & $34 \%(20)$ & 58 \\
Medical and dental & $41 \%(58)$ & $59 \%(82)$ & 140 \\
Allied healthcare professionals & $40 \%(28)$ & $60 \%(43)$ & 71 \\
Health scientist & $34 \%(5)$ & $66 \%(10)$ & 15 \\
Ambulance staff & $12 \%(1)$ & $88 \%(7)$ & 8 \\
Total & 217 & 172 & 389 \\
\hline
\end{tabular}

Source: Created by the authors. 
of the overall NHS workforce (National Health Service England 2014). The heavy bias towards females in the organisation as a whole is matched by the predominance of female volunteers in most staff cadres. For example, only $10 \%$ of nurses, midwives and health visitors in the NHS are male (NHS 2016), and this proportion is reproduced in our volunteer sample $-10 \%$ of male nurses and midwives had volunteered or worked overseas. Similarly, the overall proportions of male and female doctors in the NHS are currently relatively balanced, with $55 \%$ male and $45 \%$ female (National Health Service 2016). Our sample revealed that the numbers of male and female volunteers in this cadre also broadly followed this trend (59\% male and $41 \%$ female). What this appears to suggest is that the predominance of female healthcare workers noted in many locations may be due more to the fact that there are proportionately more women working in this field (e.g. nurses). It is not that women per se are more inclined to become involved, or that it is seen as a particularly 'female' activity (Fig. 2.1).

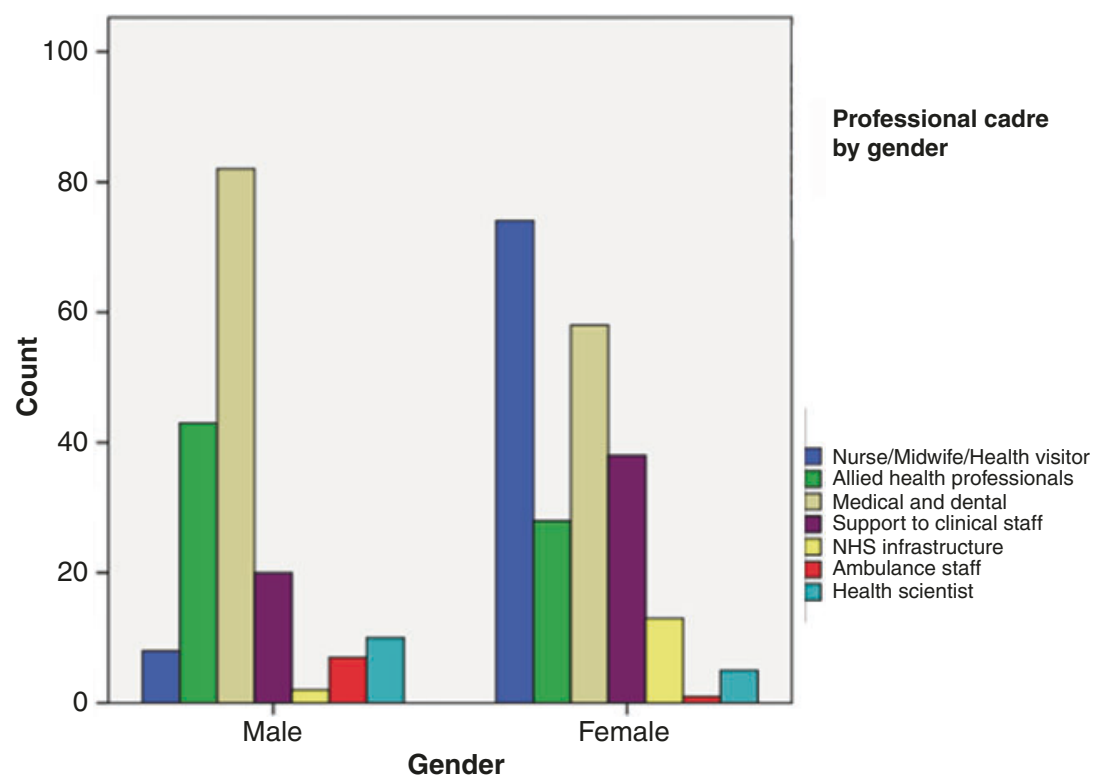

Fig. 2.1 Professional cadre by gender

Source: Created by the authors. 


\section{Nationality}

Although nationality data for the NHS workforce is officially collected (NHS digital 2016), it is currently categorised by the country of origin, rather than under the socio-demographic headings we required (i.e. British, European, Non-EU National). We derived approximate equivalent proportions by manually assigning the 212 countries in the official workforce data to our nationality categories. We acknowledge that this is only likely to give a broad approximation of current levels as there is a degree of ambiguity over where many locations might be categorised, and further bias will be introduced by the high number of staff who are officially listed as 'nationality unknown' $(22 \%)$. However, even with these caveats, the proportion of staff in our survey sample (column B, Table 2.6) does appear to reflect the levels found in the workforce overall (column A, Table 2.6). The major difference is the number of Europeans listed. Staff from European countries accounted for around $2 \%$ of the total NHS workforce, whereas our sample included just over $12 \%$. Given that it is limited to a single category, this difference may reflect local socio-demographic conditions and is also likely to be influenced by the significant number of 'unknowns' $(22 \%)$ in the national data. Significantly, the proportion of staff in our sample who had volunteered (column C, Table 2.6/Fig. 2.2) is closely matched by the makeup of the entire sample (column B, Table 2.6). This appears to indicate that in the healthcare sector the propensity to volunteer or work overseas is not dependent on country of origin.

Table 2.6 Nationality of NHS staff and survey respondents compared

\begin{tabular}{llll}
\hline Nationality & $\begin{array}{l}\text { (A) Approximate } \\
\text { proportion of NHS } \\
\text { workforce* }\end{array}$ & $\begin{array}{l}\text { (B) Proportion } \\
\text { of overall } \\
\text { sample }\end{array}$ & $\begin{array}{l}\text { (C) Proportion of } \\
\text { staff who had } \\
\text { volunteered }\end{array}$ \\
\hline $\begin{array}{l}\text { British } \\
\text { European }\end{array}$ & $\begin{array}{l}(70 \%) 850000 \\
(2 \%) 24500\end{array}$ & $\begin{array}{l}(80.6 \%) 734 \\
(11.7 \%) 107\end{array}$ & $\begin{array}{l}(78.4 \%) 305 \\
(12.1 \%) 47\end{array}$ \\
$\begin{array}{l}\text { Non-EU national } \\
\text { (developing country) }\end{array}$ & $(5 \%) 62000$ & $(6.5 \%) 59$ & $(6.7 \%) 26$ \\
$\begin{array}{l}\text { Non-EU national } \\
\text { (developed country) }\end{array}$ & $(1 \%) 9000$ & $(1.1 \%) 10$ & $(2.6 \%) 10$ \\
$\begin{array}{l}\text { Other/unknown } \\
\text { Total }\end{array}$ & $(22 \%) 264000$ & $(0.1 \%) 1$ & $(0.3) 1$ \\
\hline
\end{tabular}

Source: Created by the authors. 


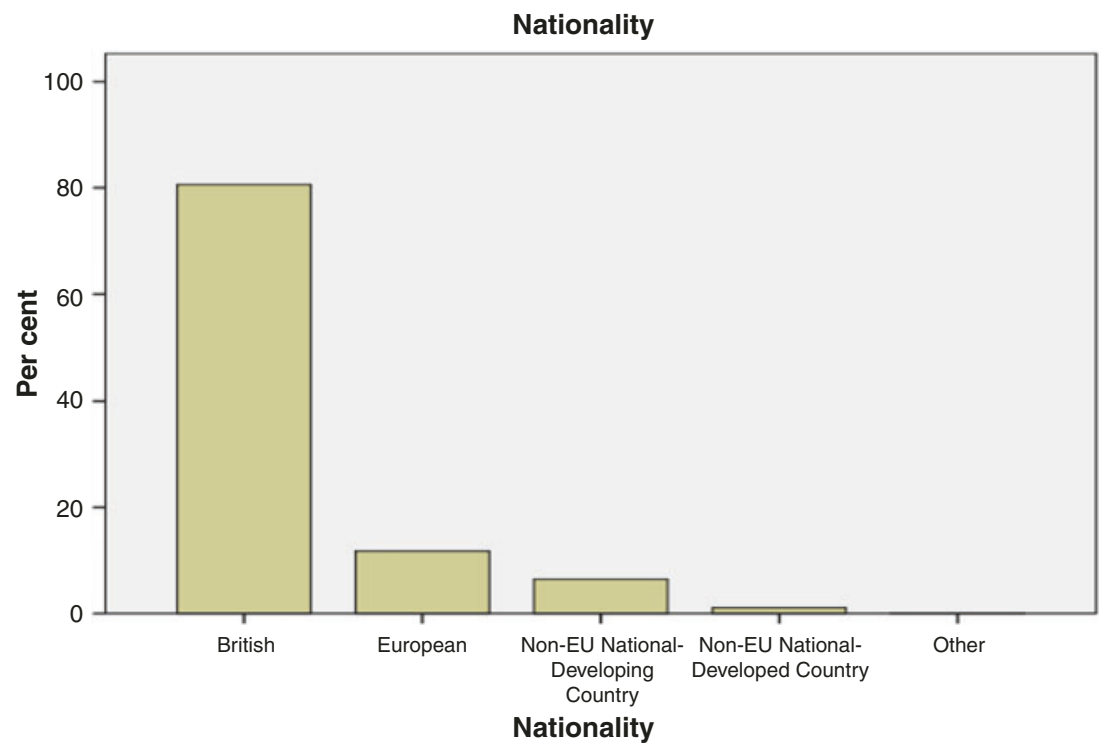

Fig. 2.2 Proportion of surveyed staff who had volunteered (column C)

Source: Created by the authors.

\section{Career Stage}

Table 2.7 illustrates the gender split within the survey, cross-tabulated by career stage. It can be seen that most males took an international placement while they were students (33\% of male volunteers) followed by early career $(26 \%)$ and mid-career (22\%). The remaining 19\% were split between pre-university $(6 \%)$, experienced $(11 \%)$ and post-retirement $(2 \%)$. Women also tended to favour international placements while they were students (41\%), with $31 \%$ going during their early career, and $14 \%$ at mid-career stage (Fig. 2.3):

Overall then, the survey indicated that the majority of overseas work or volunteering activity takes place during the early stages of people's careers, particularly during student and early career phases. For clinical staff, who may to some extent have opportunities to do this kind of activity built into their training, this is to be expected. For other staff cadres too, the period during which people traditionally have more freedom (i.e. time removed from the inevitable build-up of commitments such as starting a family) to 
Table 2.7 Career stage while working or volunteering in another country

\begin{tabular}{lll}
\hline Career stage while abroad & \multicolumn{1}{c}{ Male } & Female \\
\hline Pre-university & $(6 \%) 11$ & $(6 \%) 13$ \\
Student & $(33 \%) 56$ & $(41 \%) 88$ \\
Early career & $(26 \%) 46$ & $(31 \%) 68$ \\
Mid-career & $(22 \%) 38$ & $(14 \%) 31$ \\
Experienced & $(11 \%) 18$ & $(7 \%) 15$ \\
Post-retirement & $(2 \%) 3$ & $(1 \%) 2$ \\
Totals & 172 & 217
\end{tabular}

Source: Created by the authors.

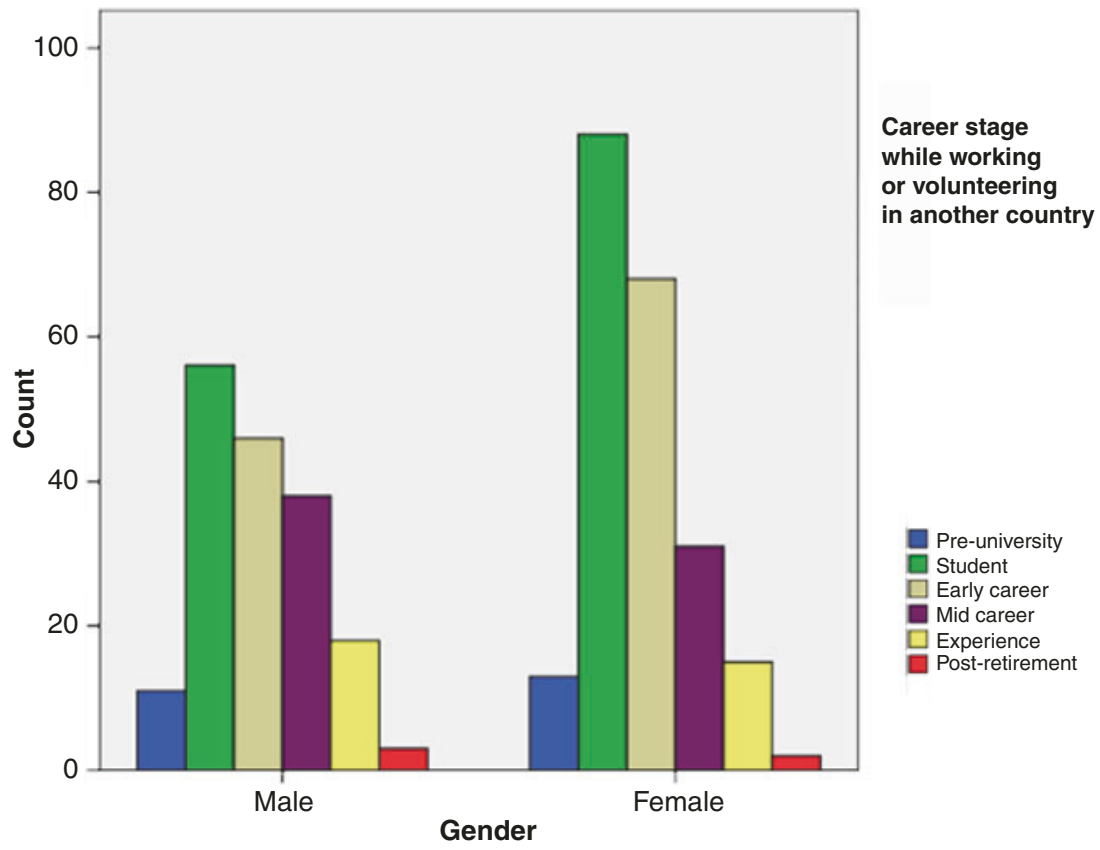

Fig. 2.3 Career stage while working or volunteering in another country Source: Created by the authors. 
engage with a spell abroad often coincides with these early career stages. Of course, not all staff follow the conventional route straight from education into training, and whereas this direct path may be the norm for medics, for other cadres, the process can be much more circuitous. Many people come to nursing, for example, after working in other careers for a period, and this obviously has implications in terms of how they may be able to deal with their other commitments. Others, like some of the midwives we interviewed for the qualitative strand of the study, had reached a point in their careers where their personal commitments had lessened and they were able to consider some time away. Kelly told us:

I'd been a midwife for a long time and I wanted a year out. So I applied to join VSO and got in. I was just doing all that sort of stuff and then I saw [a project in Uganda] so I came out here instead. I've got two grown up boys. I think you either come before you've got children/family, so there's a lot of young people. Or like me, our kids are grown up and we can just walk out.

Sandra, an experienced midwife with grown-up children, found herself in a similar position:

I have always thought about doing something with my career or profession. Take some time out and do something with it. And I had been a midwife for a very long time, and I was thinking I have to do development, something in developing countries with it. It was just a thought really. I thought if I did this, my CV would look a lot different and I might get out of working nights and delivering babies.

\section{Length of Stay}

For the purpose of the survey, we defined length of stay as short-term (under a week); medium-term (over two weeks); long-term (over three months) and extended or settlement (over one year). On average, the most popular length of stay for an overseas placement or voluntary work was medium-term, with $50 \%$ of respondents indicating that they stayed for up to three months.

It was much less usual for staff to report stays of over one year; only $8 \%$ indicated that they had been away for over a year. In terms of the gender breakdown, males tended to favour medium-term placements $(46 \%)$ followed by long-term stays (24\%). Eighteen per cent of males reported a short-term stay. In comparison, just over half (52\%) females took a 
Table 2.8 Length of placement stay by gender

\begin{tabular}{lllc}
\hline Length of time abroad & \multicolumn{1}{c}{ Male } & Female & Overall proportion (M and FM) \\
\hline Short term & $(18 \%) 31$ & $(15 \%) 33$ & $(16 \%) 64$ \\
Medium term & $(46 \%) 80$ & $(52 \%) 114$ & $(50 \%) 194$ \\
Long term & $(24 \%) 41$ & $(19 \%) 42$ & $(21 \%) 83$ \\
Extended & $(8 \%) 13$ & $(9 \%) 18$ & $(8 \%) 31$ \\
Other & $(4 \%) 7$ & $(5 \%) 10$ & $(5 \%) 17$ \\
Totals & 172 & 217 & 389 \\
\hline
\end{tabular}

Source: Created by the authors.

medium-term placement; 19\%, a long-term and 15\%, a short-term placement. Respondents who chose to make an extended stay were similarly matched in terms of gender: $8 \%$ were male and $9 \%$ were female. Overall, gender does not appear to have a great deal of impact on length of stay. The proportion of males and females in each time frame closely matches the percentages in the overall sample (Table 2.8).

\section{Age Group and Length of Stay}

Table 2.9 and Fig. 2.4 provide the age group of staff cross-tabulated against length of stay. It can be seen that the majority of respondents engaged in international placement were from the age group 'below 25' to ' $41-50$ ', which equates to 288 out of a total of 389 respondents (74\%). 94 respondents, or $50 \%$, engaged in medium-term placements. Overall, medium-term placements were the most popular, with a total of $49 \%$ of respondents across all age groups. Settlement/extended stays represented the smallest discrete group, with $8 \%$ respondents.

In many ways, the data relating to the age groups within which staff routinely fall when they work abroad appear to reflect socio-demographic conventions. The majority of staff with overseas experience, for example, come from the below 25 age group, and those who were 41-50. Almost half of these (49.9\%) reported taking a medium-term placement. Mediumterm placements were defined as over two weeks, but less than three months, and as such represent a period away which may be incorporated into the ongoing training and employment, without necessarily causing too much disruption. It is also a time frame that meshes conveniently with commercially available, medically focused, student placement schemes. In fact, many such schemes are clearly market driven and are designed to be 
Table 2.9 Length of stay by age group

\begin{tabular}{llllll}
\hline Age group & Short term & Medium term & Long term & Extended & Other \\
\hline Below 25 & $(22 \%) 14$ & $(21 \%) 41$ & $(11 \%) 9$ & $(10 \%) 3$ & $(12 \%) 2$ \\
$26-30$ & $(8 \%) 5$ & $(10 \%) 19$ & $(12 \%) 10$ & $(3 \%) 1$ & $(17 \%) 3$ \\
$31-40$ & $(17 \%) 11$ & $(23 \%) 44$ & $(22 \%) 18$ & $(29 \%) 9$ & $(29 \%) 5$ \\
$41-50$ & $(25 \%) 16$ & $(18 \%) 36$ & $(31 \%) 26$ & $(35 \%) 11$ & $(30 \%) 5$ \\
$51-60$ & $(9 \%) 6$ & $(11 \%) 22$ & $(11 \%) 9$ & $(13 \%) 4$ & $(0 \%) 0$ \\
$61-70$ & $(14 \%) 9$ & $(14 \%) 27$ & $(9 \%) 8$ & $(10 \%) 3$ & $(12 \%) 2$ \\
$71+$ & $(5 \%) 3$ & $(3 \%) 5$ & $(4 \%) 3$ & $(0 \%) 0$ & $(0 \%) 0$ \\
Totals & 64 & 194 & 83 & 31 & 17 \\
\hline
\end{tabular}

Source: Created by the authors.

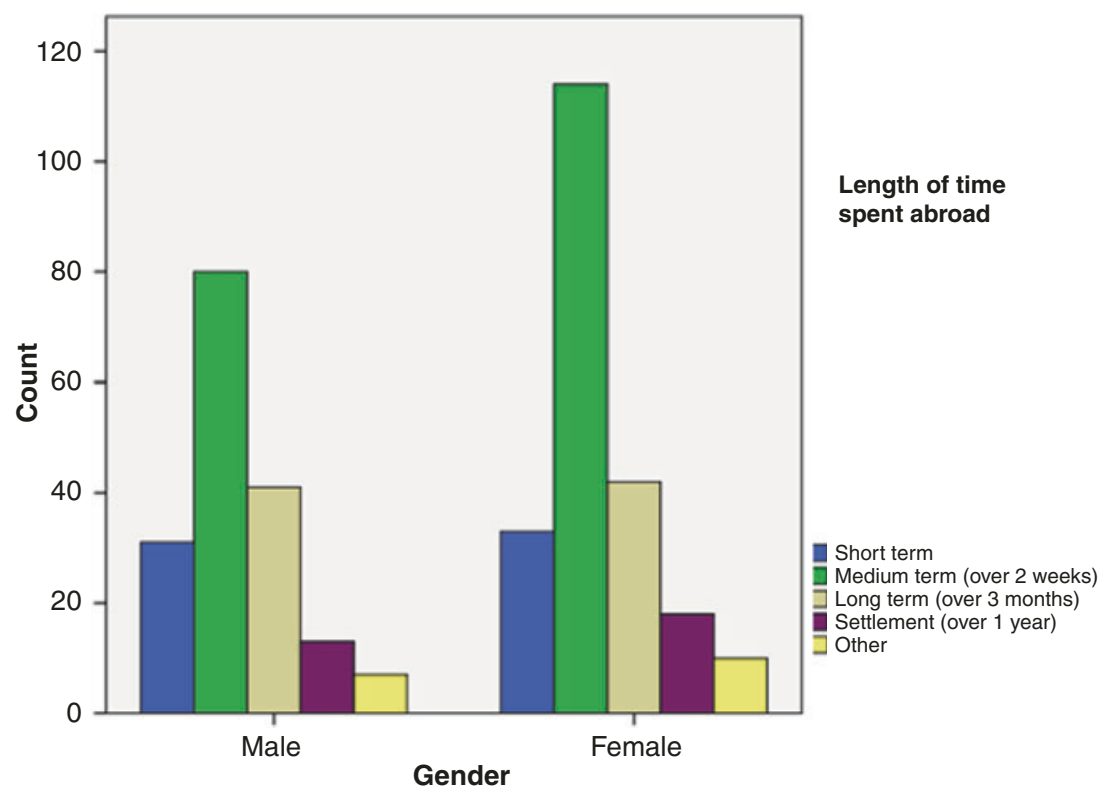

Fig. 2.4 Length of time abroad

Source: Created by the authors. 
as attractive as possible to their potential customers. In terms of cadres, for example, it tends to be doctors who are able to take longer periods abroad. However, as this anaesthetist told us, the pathway to taking a placement is not always straightforward, even for this group:

I wanted to do volunteering for a long time. I wanted to do it in an early stage of my life but I never quite did it, and although the GMC and the Royal College of Anaesthetists, and the various bodies say yeah, we support volunteering, we support working in developing countries, my individual deanery, my individual school was dead-set against it. I think they've been dead-set against it for about two years. So now I've been trying to build it in to a training placement by taking time out unrecognised for training. I've just been hitting brick walls to a point where they just kept on changing the goal posts. This is something I've got an email chain about going back about two years. When I actually asked them about wanting to do something like this, I got so frustrated that I ended up just making a decision to do my own thing. I did have a volunteer placement in Ethiopia. So I resigned my NHS job because I felt so disenfranchised and I thought well if I don't do it now, then when am I going to do it? I can always re-join registrar training, I can always get my accreditation another way.

\section{Multiple Placement Experience}

In our sample, multiple placement experiences tended to be relatively unusual. Only 10 respondents reported three periods of overseas activity, and only six of those with overseas experience reported four. All of those with multiple placement experiences came from the three staff groups incorporating midwife / nurse/health visitor ( 3 with 3 placements, and 3 with 4 placements); allied HCP (2 with 3 placements and 1 with 4 placements), and medical and dental (5 with 3 placements and 2 with 4 placements), respectively.

The issue of staff who engage in multiple placements, or periods of voluntary work abroad, is revealing. Again, in our sample, it was the medical and dental, nursing, and allied healthcare professional cadres where activity was focused. None of the other staff groupings were represented. This skewing of multiple placements towards these groups - and by extension, the employment and socio-demographic conditions which underpin them - may again be a reflection of the way in which medical training and career structuring within the NHS allow these cadres the freedom to engage in such activity. 


\section{SUMMARY}

In this chapter, we have outlined the findings from our NHS staff volunteering and overseas placement survey. This formed a discrete component of the MOVE study. The survey was primarily intended to capture a snapshot of current levels of volunteering and overseas placement activity across NHS staff grades in the North West, and we would argue that we achieved this. We are also confident that our broader aim of being able to use our findings to give a rough indication of the position across the whole of the NHS has been fulfilled. Like any large national organisation, the NHS is fairly homogenous in terms of the way its local structures are organised. The relative staffing levels we were able to capture are therefore likely to be reproduced across the organisation as a whole. By extension, levels of volunteering and overseas placement activity amongst these staff at a regional level are likely to be reproduced nationally. In the context of the NHS, it has traditionally been trainee doctors who were most likely to engage with a period of work, or placement overseas, and our survey reflects this trend. Nurses and midwives too have more recently begun to take advantage of slightly more flexible employment arrangements which have given them easier access to such placements within their career structure, and this is also reflected in our sample. In line with established NHS management and training models, our survey showed that although some degree of overseas placement activity is undertaken by a relatively high proportion of NHS staff, such activity is heavily skewed towards higher clinical staff grades. However, significant numbers of allied health professionals and equivalent non-clinical cadres also report overseas experience, and if current initiatives gain momentum, we would anticipate that these numbers will continue to rise.

Open Access This chapter is licensed under the terms of the Creative Commons Attribution 4.0 International License (http://creativecommons.org/licenses/ by $/ 4.0 /$ ), which permits use, sharing, adaptation, distribution and reproduction in any medium or format, as long as you give appropriate credit to the original author(s) and the source, provide a link to the Creative Commons license and indicate if changes were made.

The images or other third party material in this chapter are included in the book's Creative Commons license, unless indicated otherwise in a credit line to the material. If material is not included in the book's Creative Commons license and your intended use is not permitted by statutory regulation or exceeds the permitted use, you will need to obtain permission directly from the copyright holder.

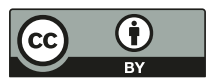

